\title{
Characterization of CdTe+Mn crystals depending on doping procedure
}

\author{
E.S. Nikoniuk ${ }^{1}$, Z.I. Zakharuk ${ }^{2}$, I.M. Rarenko², M.I. Kuchma ${ }^{1}$, I.M. Yurijchuk ${ }^{2}$ \\ ${ }^{1}$ Rivne State Polytechnic University, 11 Soborna vul., 33000 Rivne, Ukraine \\ Phone: +38(0362)230420,e-mail:didfrost@ukrwest.net \\ ${ }^{2}$ Chernivtsi National University, 2 Kotsyubyns'kogo vul., 58012 Chernivtsi, Ukraine \\ Phone: +38(0372)584875, e-mail:microel@chnu.cv.ua
}

\begin{abstract}
Electrophysical properties of $\mathrm{CdTe}+\mathrm{Mn}$ crystals grown by three different doping scheme of manganese introduction were studied. It was found that the properties of the CdTe crystals doped with Mn strongly depend on both the initial manganese concentration and the doping procedure. Introduction of $\mathrm{Mn}$ in above-stoichiometric limit in concentration of $C_{0}<10^{19} \mathrm{~cm}^{-3}$ gives $n$-type crystals. When manganese concentration is of $C_{0} \geq 10^{19} \mathrm{~cm}^{-3}$ electron conductivity is not observed so as in the $\mathrm{Cd}_{1-\mathrm{x}} \mathrm{Mn}_{\mathrm{x}} \mathrm{Te}$ solid solution crystals. A model explaining this phenomenon is proposed. Although manganese impurity in the CdTe crystals doesn't reveal any electrical activity it provides a formation of above-stoichiometric cadmium in electrically active positions $\mathrm{Cd}_{\mathrm{i}}$ and as a component of precipitates. An influence of above-stoichiometric cadmium is determined both by manganese concentration and by doping schemes, as well as by annealing and cooling temperature conditions of the doped samples.
\end{abstract}

Keywords: CdTe, manganese, crystal growth, acceptors, donors, precipitates, conductivity, annealing.

Paper received 23.01.03; accepted for publication 16.06.03.

In recent years, Mn-based II-VI semiconductors have attracted considerable attention as a promising material for preparing of quantum structures which effectively localize charge carriers [1, 2]. It is known that an introduction of manganese into cadmium telluride crystals doesn't produce levels in the forbidden band of cadmium telluride, so manganese impurity should be electrically neutral [3]. However, electrophysical studies of the $\mathrm{Cd}_{1-\mathrm{x}} \mathrm{Mn}_{\mathrm{x}} \mathrm{Te}$ $(\mathrm{x}<0.1)$ crystals indicate that introduction of $\mathrm{Mn}$ in above-stoichiometric limit gives n-type crystals with initial manganese impurity concentration of $C_{0}<10^{19} \mathrm{~cm}^{-3}$ [4]. When manganese concentration is of $C_{0} \geq 10^{19} \mathrm{~cm}^{-3}$ electron conductivity is not observed so as in the $\mathrm{Cd}_{1-\mathrm{x}} \mathrm{Mn}_{\mathrm{x}} \mathrm{Te}$ solid solution crystals [4]. Change of cadmium telluride conductivity type with concentration of manganese has not been fully investigated. Our further studies have shown that at $C_{0} \geq 10^{19} \mathrm{~cm}^{-3}$ and x $\leq 0.10$ $\mathrm{Cd}_{1-\mathrm{x}} \mathrm{Mn}_{\mathrm{x}}$ Te crystals reveal exclusively $p$-type conductivity, which is controlled by deep acceptors with energy of $E_{\mathrm{V}}+(0.12 \div 0.70) \mathrm{eV}$. But for concentrations of $C_{0}<10^{19} \mathrm{~cm}^{-3}$ the results are ambiguous and strongly depend on the loading scheme of the initial components. The purpose of the present paper is to clarify this problem.
Crystals were obtained with the use of three different schemes of components loading:

scheme I $-(\mathrm{Cd}+\mathrm{Te})+\mathrm{Mn}$ - loading of initial $\mathrm{Cd}$ and Te components into a container in stoichiometric relationship and loading in addition a manganese weight;

scheme II $-\mathrm{Cd}(1-\mathrm{x})+\mathrm{Mn}(\mathrm{x})+\mathrm{Te}-$ loading of components according to a solid solution proportion;

scheme III - CdTe+Mn - loading of previously synthesized stoichiometric $\mathrm{CdTe}$ and adding a manganese weight.

The growth and synthesis of CdTe:Mn single crystals have been carried out in evacuated quartz ampoules covered with pyrolitic graphite, while synthesis and growth of the $\mathrm{Cd}_{1-\mathrm{x}} \mathrm{Mn}_{\mathrm{x}} \mathrm{Te}$ solid solutions have been performed in glass-graphite containers. Single crystals were grown by Bridgman methods in heaters with temperature gradient on crystallization front of $10-15^{\circ} \mathrm{C} / \mathrm{cm}$ and crystallization velocity of $2 \mathrm{~mm} /$ hour.

Hall coefficient $\left(R_{H}\right)$ and specific conductivity measurements were carried out by standard methods in temperature interval of $77-300 \mathrm{~K}$. Activation energies were determined from the slope of linear part of $\lg \left(R_{\mathrm{H}} T^{3 / 2}\right)=$ $=f\left(10^{3} / T\right)$ experimental dependence. Structure perfection monitoring of the grown crystals has been carried out by X-ray spectroscopy, and microanalysis of crys- 


\section{E.S. Nikoniuk et al.: Characterization of $\mathrm{CdTe}+\mathrm{Mn}$ crystals depending on ...}

tals composition has been performed by electron microanaliser REM-101M.

In Table 1 we present electrical parameters of the samples prepared from the crystals which were grown using different schemes of manganese loading. Different behaviour of manganese impurity in different doping schemes may have an explanation in close enthalpy values of the CdTe and MnTe compounds, that causes ambiguity of the Mn introduction mechanism in CdTe.

It can be seen from Table 1 that the doping according to the scheme I at $C_{0}<10^{19} \mathrm{~cm}^{-3}$ gives exclusively n-type conductivity. Crystals conductivity in this case is controlled by shallow donors $D_{1}\left(\varepsilon_{\mathrm{D}} \leq 0.02 \mathrm{eV}\right)$ and free carriers concentration is of $10^{14}-10^{15} \mathrm{~cm}^{-3}$. One can observe a well define tendency: carriers concentration decreases with an increase of manganese concentration $C_{0}$. So far segregation coefficient of $\mathrm{Mn}$ in $\mathrm{CdTe}$ is close to unity real Mn concentration in crystal matrix is close to $C_{0}$ at all values of $g$. Here $g$ is a relative position of the sample in the ingot: $g=l / L$, where $l$ - position of the sample counting off from the ingot beginning, $L$ - length of the ingot. Temperature dependencies of carrier mobility were analyzed in the model that accounts for the scattering by optical phonons and isolated ionized centers (donors and compensating acceptors). Such dependencies are denoted in the Table 1 as normal and are characterized by monotonic increase of $\mu_{\mathrm{n}}$ with temperature low- ering. Very often at high values of $C_{0}$ it is necessary to take into account a decrease of mobility caused by reducing of effective crystals volume due to the presence of the regions which are impenetrable for electrons [5].

Concentration of electrically active centers $N_{\mathrm{J}}$, determined from temperature dependence of electron mobilities, doesn't exceed $2 \cdot 10^{16} \mathrm{~cm}^{-3}$. Thus, there is a relation between initial manganese concentration in the melt $\mathrm{C}_{0}$, concentration of electrically active centers $N_{\mathrm{J}}$, and concentration of free carriers $n: C_{0}>>N_{\mathrm{J}}>>n$. This relation unambiguously indicates that manganese impurity does not act electrically, but favour a formation of strongly compensated shallow donors $D_{1}$ with concentration $\sim 10^{16} \mathrm{~cm}^{-3}$. We suppose that intrinsic defects -interstitial cadmium atoms $\mathrm{Cd}_{i}-$ are responsible for $D_{1}$ donors. Crystals doped according to the scheme I can be presented formally as $\mathrm{Cd}_{1-\mathrm{x}} \mathrm{Mn}_{\mathrm{x}} \mathrm{Te}+\mathrm{Cd}$, where concentration of above-stoichiometric cadmium is comparable with manganese concentration $C_{0}$. As shown in [6] only small fraction of above-stoichiometric cadmium in CdTe is in the interstitial position $\mathrm{Cd}_{\mathrm{i}}$, the rest of above-stoichiometric cadmium atoms forms precipitates of submicron size. The effect of precipitate is the stronger the greater concentration of above-stoichiometric cadmium. Therefore, only the beginning of the ingot reveals weak electron conductivity, the rest of the ingot gives p-type samples which conductivity is controlled by known acceptors $A_{2}$

Table 1. Electrophysical parameters of $\mathrm{CdTe}+\mathrm{Mn}$ crystals for different doping scheme of manganese introduction

\begin{tabular}{|c|c|c|c|c|c|c|c|c|}
\hline \multirow{2}{*}{$\begin{array}{l}\text { Crystal } \\
\text { number }\end{array}$} & \multirow[t]{2}{*}{$C_{0}, \mathrm{~cm}^{-3}$} & \multirow{2}{*}{$\begin{array}{l}\text { Doping } \\
\text { scheme }\end{array}$} & \multirow{2}{*}{$\begin{array}{l}\text { Position of the } \\
\text { sample in the ingot, } g\end{array}$} & \multicolumn{3}{|c|}{$T=295 \mathrm{~K}$} & \multirow{2}{*}{$\begin{array}{l}\text { Donors } \\
\text { (acceptors) }\end{array}$} & \multirow{2}{*}{$\begin{array}{l}\text { Character } \\
\text { of } \mu(T)\end{array}$} \\
\hline & & & & $\begin{array}{l}\text { Conducti- } \\
\text { vity type }\end{array}$ & $\begin{array}{l}\text { Carriers } \\
\text { concentra- } \\
\text { tion, } \mathrm{cm}^{-3}\end{array}$ & $\begin{array}{l}\mu_{n}\left(\mu_{p}\right) \\
\mathrm{cm}^{2} /(\mathrm{V} \cdot \mathrm{s})\end{array}$ & & \\
\hline \multirow[t]{3}{*}{1} & $10^{17}$ & $\mathrm{I}$ & 0.2 & $n$ & $3.0 \cdot 10^{15}$ & 1100 & $D_{1}$ & normal \\
\hline & $10^{17}$ & I & 0.5 & $n$ & $1.5 \cdot 10^{15}$ & 1090 & $D_{1}$ & normal \\
\hline & $10^{17}$ & I & 0.9 & $n$ & $8.8 \cdot 10^{14}$ & 1080 & $D_{1}$ & normal \\
\hline \multirow[t]{2}{*}{2} & $10^{18}$ & I & 0.3 & $n$ & $1.0 \cdot 10^{15}$ & 1010 & $D_{1}$ & normal \\
\hline & $10^{18}$ & I & 0.7 & $n$ & $3.0 \cdot 10^{14}$ & 980 & $D_{1}$ & normal \\
\hline \multirow[t]{2}{*}{3} & $5 \cdot 10^{18}$ & I & 0.3 & $n$ & $5.7 \cdot 10^{14}$ & 950 & $D_{1}$ & normal \\
\hline & $5 \cdot 10^{18}$ & I & 0.8 & $n$ & $1.2 \cdot 10^{14}$ & 750 & $D_{1}$ & normal \\
\hline \multirow[t]{3}{*}{4} & $10^{19}$ & I & 0.15 & $n$ & $7.7 \cdot 10^{6}$ & 50 & $D D$ & barrier \\
\hline & $10^{19}$ & I & 0.5 & $p$ & $2.0 \cdot 10^{15}$ & 70 & $A_{2}$ & normal \\
\hline & $10^{19}$ & $\mathrm{I}$ & 0.8 & $p$ & $2.0 \cdot 10^{14}$ & 65 & $A_{2}$ & normal \\
\hline 5 & $10^{18}$ & II & 0.3 & $p$ & $1.5 \cdot 10^{15}$ & 75 & $A_{2}$ & normal \\
\hline \multirow[t]{2}{*}{6} & $5 \cdot 10^{18}$ & II & 0.2 & $n$ & $1.5 \cdot 10^{17}$ & $\sim 10$ & $D D$ & barrier \\
\hline & $5 \cdot 10^{18}$ & II & 0.7 & $n$ & $3.0 \cdot 10^{14}$ & 650 & $D_{1}$ & normal \\
\hline 7 & $10^{18}$ & II & 0.4 & $n$ & $5.7 \cdot 10^{9}$ & $\leq 10$ & $D D$ & barrier \\
\hline \multirow[t]{2}{*}{8} & $10^{18}$ & III & 0.2 & $n$ & $7.7 \cdot 10^{6}$ & 90 & $D D$ & barrier \\
\hline & $10^{18}$ & III & 0.8 & $n$ & $6.9 \cdot 10^{10}$ & $\leq 10$ & $D D$ & barrier \\
\hline \multirow[t]{2}{*}{9} & $4 \cdot 10^{18}$ & III & 0.3 & $p$ & $3.0 \cdot 10^{12}$ & 7 & $D A$ & barrier \\
\hline & $4 \cdot 10^{18}$ & III & 0.8 & $p$ & $3.0 \cdot 10^{16}$ & 65 & $A_{1}$ & normal \\
\hline
\end{tabular}




\section{E.S. Nikoniuk et al.: Characterization of CdTe+Mn crystals depending on ...}

$\left(\varepsilon_{\mathrm{A}} \approx 0.12 \mathrm{eV}\right)$. Later we will show that above-stoichiometric cadmium is also present in the p-type crystals, but in electrically inactive state as a component of precipitates.

Crystals doped according to the schemes II, III should have less possibilities to form above-stoichiometric cadmium. This fact and also possible tellurium inclusions may cause wide variations of electrical parameters of the samples even in the same ingot (see Table 1). Such crystals are characterized by strong axial and radial inhomogeneity of electrical parameters. In semi-insulating samples, which conductivity is controlled by deep donors $(D D)$ or deep acceptors $(D A)$, carrier mobility at $295 \mathrm{~K}$ is abnormally low, and its temperature dependence has a barrier character - i.e. it exponentially decreases with temperature lowering. It means that drift barriers exist, that are formed due to overlapping space charge regions caused by local inhomogeneities in spacious distribution of electrically active defects [7].

Heating the crystals up to $t>100^{\circ} \mathrm{C}$ is accompanied by complicate isothermal changes in carriers concentration, which for different samples can be explained through a formation or a decomposition of cadmium precipitates. That is also valid for the crystal grown according to the scheme I with $C_{0}=10^{19} \mathrm{~cm}^{-3}$ (crystal N 4 from Table 1). In the p-type samples relaxation processes take place (analogous to the studies carried out in $\mathrm{CdTe}+\mathrm{Cd}$ ), which are accompanied by an isothermal decrease of hole concentration at $t \geq 100^{\circ} \mathrm{C}$. This means a decomposition of shallow cadmium precipitates.

Therefore, defect-impurity system of the crystals doped according to the schemes II and III is nonequilibrium. Obviously, this is valid also for high post-growth cooling temperatures. Thus, long-term annealing of doped samples should be accompanied by the radical change in defect-impurity system and accordingly by a change of its electrical parameters. The annealing of doped samples at $500{ }^{\circ} \mathrm{C}$ during 50 hours changes over their conductivity type from $\mathrm{p}$ to n-type, electron conductivity of these samples is controlled by shallow donors $D_{1}$ (Table 2). Let's note that such an annealing of undoped p-type samples never change their conductivity type, so we suggest cadmium precipitates are being a source of donors.
Electron concentration in annealed samples takes the same values as in the crystals doped according to the scheme I (see Table 2), but electron mobilities are very sensitive to the doping scheme. If for the samples doped according to the scheme III (which gives a possibility to form above-stoichiometric cadmium although in less amount than in scheme I) dependence of $\mu(T)$ has normal behaviour, for crystal doped according to the scheme II (which, in principle, could not give above-stoichiometric cadmium) dependence $\mu(T)$ has unambiguously barrier character. Although not everything is clear enough, we can conclude that above-stoichiometric cadmium are formed in both cases, but dimension and concentration of precipitate before annealing and degree of their disintegration at annealing differs considerably.

It is obvious that full decomposition of the precipitates is not achieved at $t_{\mathrm{a}}=500^{\circ} \mathrm{C}$. To confirm this we present the results of annealing for the sample 9 from Table $1(g=0.8)$. We have found that after annealing conductivity type doesn't change remaining $p$-type, but hole concentration decreases more than in two orders (Fig. 1, point $B)$. The reason for such a decrease could be disintegration of cadmium precipitates, that results in local inhomogeneities in the crystal. The latter conclusion can be verified by barrier character of the $\mu(T)$ dependence (Fig. 2, curve 1). In "cooling-heating" cycle hysteresis relaxation of hole concentration is observed (Fig. 1, section 1a, 2a). We observe the same hysteresis-type relaxation for CdTe: $\mathrm{Cu}$ system, but there are some differences: longterm delay takes place at point $E$, and point $P$ isn't achieved again. Such a behaviour can be understood if we suggest superposition of two processes: change of the localization of both the impurity copper atoms and the intrinsic interstitial donors $\left(\mathrm{Cd}_{\mathrm{i}}\right)$ in the lattice. In the section 1a these two processes are accompanied by emerging of additional holes. In the section $2 \mathrm{a}$ the process of $\mathrm{Cu}$ relocalization is accompanied by disappearance of holes, while the process of cadmium precipitate formation - by their emergence.

The effect of copper impurity may be connected with the probable fouling of the samples in the preparation and long-term annealing process. Concentration of $A_{2}$ and $A_{4}$ acceptor $\left(\varepsilon_{\mathrm{A} 2} \approx 0.12 \mathrm{eV}, \varepsilon_{\mathrm{A} 4} \approx 0.35 \mathrm{eV}\right)$ which

Table 2. Electrophysical parameters of $\mathrm{CdTe}+\mathrm{Mn}$ crystals annealed at $5_{00}^{\circ} \mathrm{C}$ during 50 hours

\begin{tabular}{l|l|l|l|l|l|l|l}
\hline \hline $\begin{array}{l}\text { Crystal number } \\
\text { in Table 1 }\end{array}$ & $C_{0}, \mathrm{~cm}^{-3}$ & $\begin{array}{l}\text { Doping } \\
\text { scheme }\end{array}$ & $\begin{array}{l}\text { Position of the } \\
\text { sample in the } \\
\text { ingot, } g\end{array}$ & \multicolumn{4}{|c}{ After annealing, $T=295 \mathrm{~K}$} \\
\hline & & & $\begin{array}{l}\text { Conducti- } \\
\text { vity type }\end{array}$ & $\begin{array}{l}\text { Carriers } \\
\text { concentra- } \\
\text { tion, } \mathrm{cm}^{-3}\end{array}$ & $\begin{array}{l}\mu_{\mathrm{n}}\left(\mu_{\mathrm{p}}\right), \\
\mathrm{cm}^{2} /(\mathrm{V} \cdot \mathrm{s})\end{array}$ & $\begin{array}{l}\text { Character } \\
\text { of } \mu(T)\end{array}$ \\
\hline 5 & $10^{18}$ & II & 0.5 & $n$ & $7.8 \cdot 10^{14}$ & 11 & barrier \\
\hline 6 & $5 \cdot 10^{18}$ & II & 0.2 & $n$ & $1.0 \cdot 10^{15}$ & 200 & barrier \\
\hline 9 & $10^{18}$ & III & 0.3 & $n$ & $6.9 \cdot 10^{14}$ & 720 & normal \\
\hline \hline
\end{tabular}




\section{E.S. Nikoniuk et al.: Characterization of $\mathrm{CdTe}+\mathrm{Mn}$ crystals depending on ...}

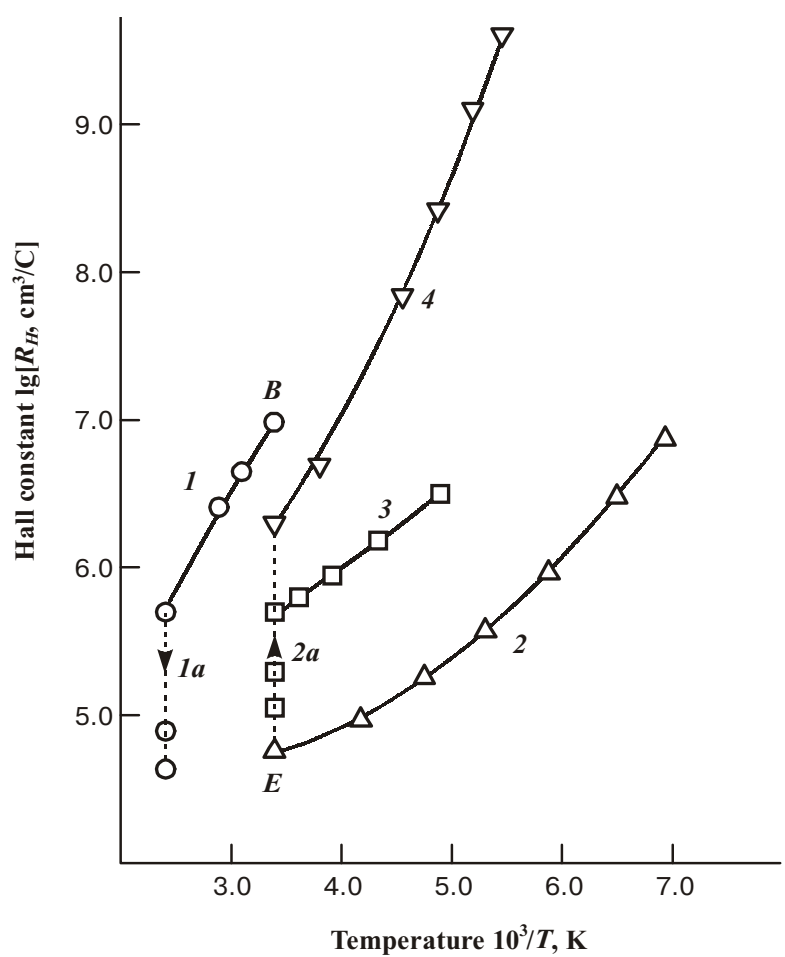

Fig. 1. Temperature dependence of Hall constant of $p$-CdTeMn sample with hysteresis-type relaxation. 1 - initial state; 2, 3, 4 - different relaxation stages at room temperature; $1 a, 2 a-$ isothermal relaxation; $B$ - beginnig point of the cycle, $E$ - end point of the cycle.

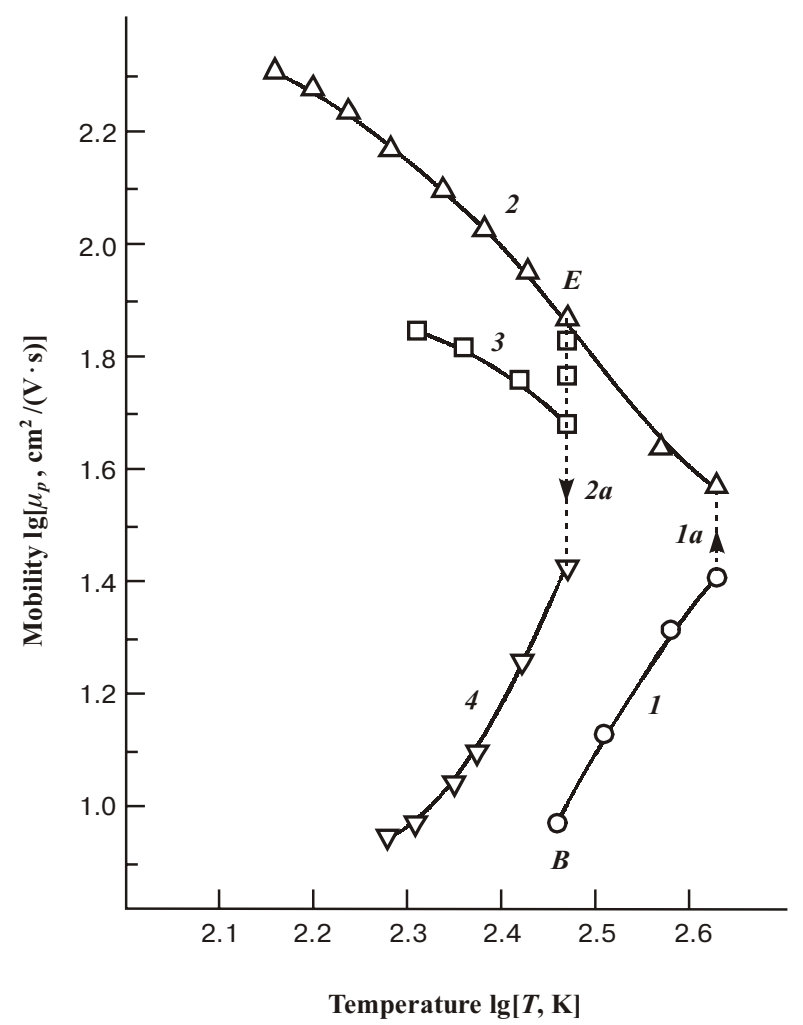

Fig. 2. Hole mobilities of $p$-CdTe-Mn sample in different relaxation stages. 1 - initial state; $2,3,4$ - different relaxation stages at room temperature; $1 a, 2 a$ - isothermal relaxation; $B$ - beginnig point of the cycle, $E$ - end point of the cycle.

$S Q O, 6(2), 2003$ control $p$-type conductivity on different relaxation stages (Fig. 2, curves 2-4) is of $10^{14}-10^{16} \mathrm{~cm}^{-3}$, that is comparable with the concentration of $\mathrm{Cu}$ and that of above-stoichiometric cadmium. Character of the $\mu(T)$ dependence changes from normal in low-resistivity state to barrier in high-resistivity one, similar to that in $\mathrm{CdTe}+\mathrm{Cd}$ crystals [6].

We can conclude, that manganese impurity in cadmium telluride crystals doesn't reveal electrical activity, but provides a formation of above-stoichiometric cadmium in electrically active positions $\mathrm{Cd}_{\mathrm{i}}$ and appears as a component of precipitates. The influence of above-stoichiometric cadmium is determined as by doping schemes and manganese concentration as well as by annealing and cooling temperature conditions of doped samples.

\section{Acknowledgements}

The financial support of the Science and Technology Center of Ukraine (grant \#1440) is gratefully acknowledged.

\section{Reference}

1. P.Kazman, Spin interactions in diluted magnetic semiconductors and magnetic semiconductor structures // Semicond. Sci.Technol. 16, R25-R39 (2001).

2. A.Haury, A.Wasiela, A.Arnoult, J.Cibert, S.Tatarenko, T.Dietl, and Y.Merle d'Aubigne, Observation of a Ferromagnetic Transition Induced by Two-Dimensional Hole Gas in Modulation-Doped CdMnTe Quantum Wells // Phys. Rev. Lett. 79, pp. 511 (1997).

3. A.Zunger, Electronic structure of $3 \mathrm{~d}$ transition-atom impurities in semiconductors, Solid State Physics 39, pp.275-464 (1986).

4. A.I.Vlasenko, V.N.Babentsov, Z.K.Vlasenko, S.V.Svechnikov, I.M.Rarenko, Z.I.Zakharuk, E.S.Nikoniuk, V.L.Shliakhovyi, Acceptors in $\mathrm{Cd}_{1-\mathrm{x}} \mathrm{Mn}_{\mathrm{x}} \mathrm{Te}(\mathrm{x}<0.1) / /$ Fiz. Techn. Poluprov. 31(8), pp.1017-1020 (1997).

5. M.V.Aleksienko, E.N.Archadieva, O.A.Matveev, About an influence of inhomogeneities on electrons mobility in cadmium telluride // Fiz.Techn.Poluprov. 4(12), pp.414-416 (1970).

6. Y.S.Nikonyuk, M.I.Kuchma, M.O.Kovalets, V.L.Schlyachovyi, Z.I.Zakharuk Relaxation processes in cadmium telluride crystals with interstitial donors // Proc. of First Ukraininan Scientific Conference on Semiconductor Physics, Odessa, 2002, p.303-304.

7. M.K.Sheikman, A.Ya.Sheak, Long-term relaxation and residual conductivity in semiconductors // Fiz.Techn.Poluprov. 10(2), pp.209-233 (1976). 